\title{
A ilusão do tempo em La Jetée, de Chris Marker
}

Felipe Arrojo Poroger

\section{Resumo}

A partir das reflexões de Friedrich Nietzsche em O eterno retorno e Jorge Luís Borges em Nova refutação do tempo, propõe-se tecer uma leitura crítica do filme La Jetée, de Chris Marker, a fim de examinar como a sua dimensão temporal dialoga com o ideário dos dois autores citados. Mais do que posicionar a obra como devedora de certa linhagem teórica - embora isso seja inevitável -, objetiva-se encontrar os pontos de convergência e choque com as propostas nietzschianas e borgianas. Para tal, optou-se por segmentar o texto em três momentos: I) breve apresentação do conceito de eterno retorno, sua formulação e dimensão doutrinária, II) exposição do tema para Borges, a crítica aos mandamentos nietzschianos e abandono da concepção do tempo como instância dotada de sentido, III) reflexão sobre a estrutura temporal de La Jetée, a partir dos conceitos discutidos.

Palavras-chave: Borges - Nietzsche - Literatura - Cinema - La Jetée. 
A cartela inicial de La Jetée (I962), de Chris Marker, apresenta a obra como sendo "a história de um homem marcado por uma imagem de infância", dia no qual presenciou um assassinato no terminal do aeroporto de Paris enquanto concentrava-se em guardar na sua memória a imagem de uma linda jovem ali presente. Anos depois, eclode a Terceira Guerra Mundial e, sendo um dos poucos sobreviventes de uma explosão nuclear, o sujeito torna-se cobaia de um experimento no qual, estimulado por eletrochoques, é lançado a alguns momentos de seu passado e apresentado a outros de seu futuro.

A breve descrição da obra em questão já aponta, de imediato, para uma reflexão sobre o tempo: o entrelaçamento entre passado, presente e futuro - e o sugerido entrelaçamento entre eles - assume importância primordial no filme. Introduzir, aqui, conceitos-chave de obras de Friedrich Nietzsche e Jorge Luís Borges é recuperar entendimentos distintos quanto a estruturas de temporalidade, de modo a sugerir como Marker insere-se nesse campo de estudo, apropriando-se destes legados filosóficos para, a partir deles, realizar contribuição singular em formato audiovisual.

Logo nas primeiras linhas de $O$ eterno retorno, Nietzsche (I978) vale-se de uma equação de dois termos para formular a sua teoria: força e tempo. Embora a definição de força seja controversa e complexa - sendo necessária outra dissertação somente para melhor pensá-la -, cabe aqui entendê-la como sendo a responsável pela criação de todas as situações e combinações passíveis de ocorrência em uma dimensão espaço-temporal. Ainda que a quantidade de tais eventos seja "descomunalmente grande e praticamente imensurável" (NIETZSCHE, I978, p. 385), não se pode, no entanto, segundo o autor, afirmar que seja infinita. O mesmo, no entanto, não ocorre com o tempo; este, sim, seria infinito; nele, "a força seria eternamente igual e eternamente ativa" (NIETZSCHE, I978, p. 439).

Se o mecanismo criador dos desenvolvimentos possíveis (a força) é limitado - ainda que eternamente atuante - e o meio no qual atua (o tempo) é infinito, conclui-se que, em dado momento, haverá repetições.

[...] até esse instante já transcorreu uma infinidade, isto é, é necessário que todos os desenvolvimentos possíveis já tenham estado aí. Consequentemente, o desenvolvimento deste instante tem de ser uma repetição, e também o que o gerou e o que nasce dele, e assim por diante, para a frente e para trás! Tudo esteve aí inúmeras vezes (NIETZSCHE, I978, p. 385). 
Opondo-se, portanto, a uma concepção linear de tempo - muitas vezes vinculada ao discurso progressista e às esperanças na modernidade, tão caros ao contexto em que escrevia -, Nietzsche não apenas afirma uma cronologia na qual os eventos se alternam (e se repetem) em ciclos, como também a defende como doutrina: "viver de tal modo que tenhas de desejar viver outra vez é a tarefa - pois assim será em todo caso! [...] Gerações inteiras têm de edificar nele [no ensinamento] e nele tornar-se fecundas!" (NIETZSCHE, I978, p. 389).

Para o conceito de eterno retorno nietzschiano, estruturado a partir da equação força e tempo, "tudo é eterno, nada veio a ser: se houve um caos das forças, também o caos era eterno e retorna em cada anel. O curso circular não é nada que veio a ser, é uma lei originária [...]. Todo o vir-a-ser está no interior do curso circular e da quantidade da força" (NIETZSCHE, I978, p. 44I).

Ainda que Nietzsche tenha proposto, assim, uma concepção temporal distinta daquela comumente aceita à sua época, o modelo circular por ele sugerido - cujos princípios básicos já podiam ser encontrados na filosofia pitagórica, por exemplo - não tinha por intenção romper com a noção de que o tempo - seja em sua linearidade ou circularidade - obedeceria a algum sentido. O mesmo, no entanto, não pode ser dito de Jorge Luís Borges (20I3b) e Nova refutação do tempo. Na crítica às teorias do filósofo alemão e na proposição de uma teoria que, como bem sugere o título da obra estudada, refuta o conceito de tempo, o ideário borgiano fornecerá instrumentos para melhor compreender o que está em jogo em La Jetée.

A Nietzsche e seu eterno retorno, não raro Borges refere-se em tom de zombaria. Em A doutrina dos ciclos, inserido na História da eternidade, o autor argentino, além de discutir a pretensa originalidade da doutrina nietzschiana - "su más reciente inventor llama del eterno retorno" (BORGES, 2009a, p. 385) -, evoca Georg Cantor e Fritz Mautner para descartá-la.

Dialogando com Georg Cantor, Borges recupera a demonstração matemática que prevê - ao contrário do que insistia Nietzsche - a existência de uma quantidade infinita de combinações possíveis: "Si el universo consta de un número infinito de términos, es rigorosamente capaz de un número infinito de combinaciones" (BORGES, 2009a, p. 386).

O filósofo argentino, na sequência, evocando Mautner, argumenta que pressupor a validade do eterno retorno implica imaginar que a sequência circular pode ser interrompida por algo novo. Afinal, se a tarefa nietzschiana consiste 
em "viver de tal modo que tenhas de desejar viver outra vez" (NIETZSCHE, I978, p. 389) - e todo querer/desejar pressupõe escolha -, logo a objeção mautneriana se explica: "atribuir la menor influencia moral, vale decir práctica, a la tesis del eterno retorno equivale a imaginar que algo pude acontecer de otro modo" (BORGES, 2009a, p. 389). Como conciliar, então, a (suposta) novidade do eterno retorno com a estrutura circular e repetitiva do tempo? A aceitação da tese de Nietzsche seria, portanto, a sua falência.

Distanciando-se da concepção nietzschiana, Borges apropria-se do idealismo de Berkeley - radicalizado por David Hume -, para o qual não seria possível comprovar a existência de um objeto fora de uma mente que o perceba (nem garantir que exista um eu fora dessa mente). Vale-se, também, do princípio dos indiscerníveis de Leibniz (se x e y têm as mesmas propriedades, eles seriam idênticos) para, assim, pensar e formular uma outra concepção temporal.

Negando-se o espírito e a matéria, que são continuidades, negando-se também o espaço, não sei que direito temos a essa continuidade que é o tempo [...] Hume negou a existência de um espaço absoluto, em que cada coisa tem seu lugar; eu, a de um tempo único, em que se encadeiam todos os fatos (BORGES, 20I3b, p. 203).

Diferentemente de Nietzsche, portanto, que afirma a circularidade - preservando, assim, certos fundamentos do tempo-, Borges nega tanto que se possa falar em sucessão de eventos quanto que exista coexistência e sincronismos possíveis entre dois tempos; o filósofo argentino sustenta o tempo autônomo de instantes absolutos. Se dois sujeitos, para além de sua localização temporal- geográfica, compartilhassem das mesmas impressões, eles seriam idênticos; "os leitores fervorosos que se entregam a uma linha de Shakespeare não são, literalmente, Shakespeare?" (BORGES, 20I3b, p. 206).

Assim o espectador é introduzido a La Jetée: em um mundo, uma época, no qual o espaço está em ruínas - levando os remanescentes a viver nos subterrâneos da cidade -, dominar os segredos do tempo torna-se a esperança primeira para o retorno à época anterior à destruição. Deste modo, a recuperação forçada de fragmentos de lembranças do protagonista, acontecimento dramático central na obra, recupera a velha máxima: relembrar é reviver, aqui em sentido literal - nesta equalização, a esperança de voltar às vésperas do desastre nuclear configura-se não apenas como lembrança, mas, sim, realidade. 
Preocupação constante no imaginário de Borges, a indistinção entre memória e (a dita) realidade presente ganha no filme uma representação; em ambos, reconhece-se a soma da tradição empirista com o princípio dos indiscerníveis: os experimentos levados a cabo em La Jetée também partem do pressuposto de que a recuperação das lembranças pode reconstruir o presente.

Em certa etapa do processo, o protagonista, revendo o seu passado, constata: "ao décimo dia da experiência, começaram a surgir imagens, como confissões - um quarto real, crianças reais, pássaros reais, gatos reais”. Se, ao relembrar, o homem é tomado pelas mesmas sensações que o invadiram no momento em que as presenciou pela primeira vez, o que distingue os dois eventos? Defende-se a autonomização do instante vivido, para além da teia cronológica que os envolveria; as fronteiras entre passado e presente - se é que ainda se pode usar os termos em uma relação sucessória - são dissolvidas.

O caráter autônomo e absoluto do momento é ainda reforçado pelo fato de a moça com quem o protagonista interage nas lembranças não nutrir lembranças dele ou com ele projetar planos; o instante descola-se da cronologia e projeta-se em fragmentos independentes. Não à toa, Ghris Marker vale-se quase somente de fotos para contar uma história inserida em um formato - o cinema - cuja própria etimologia sugere movimento; a estaticidade pictórica tensiona-se com a sucessão cinematográfica, sugerindo que a continuidade das imagens (e do tempo) não é imediata - um abismo as separa e as autonomiza.

Ao final do filme, o narrador anuncia o sucesso da experiência: os cientistas parecem ter encontrado meios de regenerar a sociedade destruída. $\mathrm{O}$ protagonista, percebendo-se em vias de ser executado por aqueles que o fizeram de cobaia, pede para regressar ao instante de sua infância em que estava no aeroporto parisiense. Consegue. Mas antes de ter a chance de se aproximar da mulher cujo rosto o sensibilizava naquela manhã, ele é morto por um dos cientistas. A morte que presenciara quando criança era, portanto, a sua própria.

Fazendo de seu final uma repetição do começo, o filme parece, à primeira vista, operar em uma dimensão cíclica. Ainda que tal formulação pudesse esboçar associação imediata com o eterno retorno, a circularidade não se constrói, nesse caso, nos moldes do conceito nietzschiano; ela indica, ao invés disso, o ciclo como uma das facetas possíveis - mas não única - de um tempo descontínuo, cujo sentido é impossível de prever.

A coexistência do protagonista em duas idades parece confirmar essa compreensão: não se trata da repetição de um mesmo momento, mas sim a confluência de dois tempos independentes. De algum modo, a criança e o 
adulto, pessoas diferentes no início, tornam-se uma apenas no final, quando compartilham da mesma certeza: a de que são, ao mesmo tempo, testemunha e vítima do assassinato.

"A aterradora imensidão dos abismos do firmamento é uma ilusão, um reflexo exterior dos nossos abismos, percebidos 'num espelho'" (BORGES, 20I3a, p. I44). A citação extraída de $O$ Espelho dos Enigmas confirma a importância da especularidade para o autor: pela confluência de sensações instantâneas, dois sujeitos podem tornar-se idênticos. Não à toa, no célebre Os teólogos, a história de Aureliano e Juan de Panonia assim chega ao seu final: "Más correcto es decir que en el paraíso, Aureliano supo que para la insondable divinidad, él y Juan de Panonia (el ortodoxo y el hereje, el aborrecedor y el aborrecido, el acusador y la víctima) formaban una sola persona" (BORGES, 2009b, p. 556).

O encerramento do filme de Chris Marker, com a afirmação de que "não se pode iludir o tempo", aponta para a mesma direção: não cabe à humanidade tentar controlar a dimensão temporal, tampouco predicar a sua normatividade. Se a pretensão de iludir e manejar implicou, na narrativa, em aniquilação do sujeito, Marker parece querer nos dizer que aceitar a sua descontinuidade e autonomia torna-se meio único de sobrevivência. Como diria Léon Bloy, citado por Borges em $O$ Espelho dos Enigmas, "é duvidoso que o mundo tenha um sentido [...]. Nenhum homem sabe quem é" (BORGES, 20I3a, p. I46)

\section{Referências}

BORGES, J. L. La doctrina de los ciclos. In: El Aleph. Buenos Aires: Emecé, 2009a. (Obras completas, v. I). Los teólogos. In: . Historia de la eternidad. Buenos Aires: Emecé, 200gb. (Obras completas, v. I).

O Espelho dos Enigmas. In: Outras inquisições. Tradução de Davi Arrigucci Jr. São Paulo: Companhia das Letras, 20I3a. . Nova refutação do tempo. In: Outras inquisições. Tradução de Davi Arrigucci Jr. São Paulo: Companhia das Letras, 20I3b.

LA JETÉE. Direção: Chris Marker. Paris: Argos Films, I962. Disponível em: $<$ https://bit.ly/2KGoFWS>. Acesso em: Io jul. 2017.

NIETSZGHE, F. W. O eterno retorno. In: Obras incompletas. Tradução de Rubens Rodrigues Torres Filho. São Paulo: Abril, I978. (Coleção Os Pensadores). 
A vontade de poder. Tradução de Marcos Sinésio Fernandes e Francisco José de Moraes. Rio de Janeiro: Contraponto, 2008.

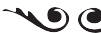

Felipe Arrojo Poroger é graduado em Filosofia pela Universidade de São Paulo.

felipeporoger@finosfilmes.com.br 